\title{
Empirical Study on Game Theory of China's Food Safety Supervision-On the Basis of Game Analysis of Government and Food Enterprises
}

\author{
Wang Mingzhe ${ }^{1}$ \\ ${ }^{1}$ School of Public Administration, Hohai University, Nanjing 211100, China \\ Mingzhewang88@163.com
}

\begin{abstract}
Since the food is the necessity that human beings live on, food safety has become the common topic which shares all human beings' concern. The food safety incidents which happened recent years have not only affected the health of people, but also had negative effects on economic development or even the social stability. Given this, the government has continuously intensified the supervision on food safety, implementing many policies like "Food Safety Project" and mandatory authentication plan of pollution-free food. In National Video and Telephone Conference of Strengthening Food Safety on June 11 $1^{\text {th }}$, 2015, Prime Minister Li Keqiang put forward that food safety concerned everyone's physical health and life safety, and it was the aspiration of the broad masses that could eat hearty and safe food, which was also the basic demand of building well-off society in an all-around way. On this background, this paper began from the game analysis of government and food enterprises, based on Game theory, Stakeholder theory and so on, to build the game model of government and food enterprises and to analyze when faced with food safety supervision, the two parties would take what measures to obtain the maximum effect. At last, the paper proposed some suggestions for policies on reforming food safety supervision system.
\end{abstract}

Keywords: Food safety supervision; Government; Food enterprises; Stakeholder; Game model

\section{Introduction}

Food safety relates to the national economy and the people's livelihood, so it not only concerns the physical health and life safety of consumers, but also has close relations with our economic development and social stability. With the development of society and science, the varieties of food are also increasing, and new products emerge in endlessly. In the meantime, issues involving food safety have got more and more attention from people. As for the importance of the food safety, our government pays high attention to it and has taken many measures, for example, Decision on Further Strengthening Food Safety issued in July, 2004 has established the dividing management system which is responsible by Ministry of Public Health, Ministry of Agriculture, State Food and Drug Administration and State Administration of Industry and Commerce, besides, in 2009, we issued the Food Safety Law of the People's Republic of China. However, owing to market transformation, local protection, weak supervision or other facts, serious food safety incidents still happens again and again. Since 2005, issues like Big-Head Baby in Fuyang, Anhui, Apple Snails in Beijing, Artificial Honey in Hubei areas, and Sudan Red Duck Egg in Beijing and Dalian have all aroused strong reaction from society. As showed in Table 1, there lists bulletins of poisoning incidents during 2010 to 2014 issued by National Sanitation and Family Planning Council, which really shocks everyone's heart. In a word, food safety has become an important issue to be solved. 
Table 1. Food Poisoning Condition of our Country During 2010 to 2014

\begin{tabular}{cccc}
\hline Year & $\begin{array}{c}\text { Food Poisoning Case } \\
\text { (Piece) }\end{array}$ & Poisoning Patients & Death Toll \\
\hline 2010 & 220 & 7383 & 184 \\
2011 & 189 & 8324 & 137 \\
2012 & 174 & 6685 & 146 \\
2013 & 152 & 5559 & 109 \\
2014 & 160 & 5657 & 110 \\
\hline
\end{tabular}

For the study of food safety, foreign countries started earlier, so they have more proven theories. Henson et. al.,[1] pointed out that the policy makers of the food safety supervision policy were the gaming results of those stakeholders like food consumers, food product enterprises and government supervision administrations, while consumers behaviors were affected by government supervision administrations and food product enterprises. Arrow et. al.,[2] said that it was necessary for government to supervise food safety, and its supervision power depended on the cost of supervision and its concrete calculation method of interests. What's more, Antle [3] has proposed the principles of realizing food safety regulation, and he divided the food information into asymmetrical incomplete information and symmetrical incomplete information. He also combined other scholars' study model to establish Meat Enterprises Theory and function model for calculating economic costs. In addition, Grossman [4] thought that consumers can't get complete information, but they can still choose safe food according to the market equilibrium with high quality and high price produced by market system. So they didn't need government to supervise food safety.

While scholars of our country have put forward their own views on government's food safety supervision from different aspects. When analyzed issues of interests among every party and their roles replacement on the chain of food product, Li Jing [5] found that China's supervision system based on horizontal coordination has ignored the fracture property of the product chain and the interests of local governments, so it can't avoid the happening of major food safety incidents. While through model and cases analysis, Wang Keshan, Li Binglong et. al., [6] concluded that the moral hazard costs borne by food producers were commonly decided by extra benefit producing unsafe food, the probability found by supervision administrations, the prospective earnings of producers and the fine for exposure. Besides, Liu Renzhong [7] held the view that the food safety supervision is a kind of pure public good, which should be provided by government. By analyzing the static game and repetitive game between government and enterprises, and introducing fine system and public satisfaction index, the increasing probability for food enterprises to choose to produce safe food has been proven. Also, it proves that food safety incident results from government pursuing economic benefit but ignoring society benefit.

Through the research methods and research process of literature above,we can find that food safety supervision is not a single choice question but a complex choice question,which needs interactive game.Therefor this article is based on Game Theory and Stakeholder Theory,construction game model between government and Food Enterprises,and analyzes game strategies of stakeholder about food safety supervision, and fills in the blanks about present studies,and provides helpful references about actual operations of food safety supervision.

\section{Materials and mMethods}

The word"game" means playing chess or gambling. Game Theory originated from 1940s, which is a kind of theory studying interactive decision. In 1984, R.E Freeman[8] definitely proposed Stakeholder Theory, and in 1988 define stakeholder as those who benefit or influence badly owing to enterprise activities, and whose rights are also 
respected or infringed because of enterprise activities. According the theories above, food safety involves three parties including government, producer and consumers, and any party's strategies choice has influence on another two parties.In this paper, it only analyzed the game between producers and government related to food safety supervision without analyzing consumer's behavior.In this game, enterprises know about the quality of food, and the supervisor is interior in information acquiring, so this is an incomplete information game. In this paper, author will introduce two types of incomplete information game. They are incomplete information static game (Static Bayesian Game) and incomplete information dynamic game (Dynamic Bayesian Game).

\subsection{Static Bayesian Game:}

2.1.1. Strategic Representation of Static Bayesian Game: Strategic representation of Static Bayesian Game among n people includes type space of participants $\Theta_{1}, \Theta_{2}, \cdots \Theta_{n}$, conditional probability $p_{1}, p_{2}, \cdots p_{n}$, type interdependent strategic space $A_{1}\left(\theta_{1}\right), A_{2}\left(\theta_{2}\right), \cdots A_{n}\left(\theta_{n}\right)$, and type interdependent function of gain and loss $u_{1}\left(a_{1}, a_{2}, \cdots a_{n} ; \theta_{1}\right), \cdots u_{n}\left(a_{1}, a_{2}, \cdots a_{n} ; \theta_{n}\right)$. On the condition that participant $i$ knows about his or her own type $\theta_{i} \in \Theta_{i}$ and conditional probability $p_{i}=p_{i}\left(\theta_{-i} \mid \theta_{i}\right)$, the game describes the uncertainty of the relations between participant $i$ and other participant type $\theta_{-i} \in \Theta_{-i}$,given that himself or herself belongs to $\theta_{i}$.Use $G=\left\{A_{1}, A_{2}, \cdots A_{n} ; \theta_{1}, \theta_{2}, \cdots \theta_{n} ; p_{1}, p_{2}, \cdots p_{n} ; u_{1}, u_{2}, \cdots u_{n}\right\}$ to representative this game.

The time order of the Static Bayesian Game is as followed, (1) natural selection type vector $\theta=\left(\theta_{1}, \theta_{2}, \cdots \theta_{n}\right)$, and in the formula, $\theta_{i} \in \Theta_{i}$. Participant i observes the $\theta_{i}$, but participant $j(\neq i)$ only knows $p_{j}\left(\theta_{-j} \mid \theta_{j}\right)$, but can not observe $\theta_{i}$. (2) If n participants choose to act in the same time, then $a=\left(a_{1}, a_{2}, \cdots a_{n}\right)$, and in the formula, $a_{i} \in \mathrm{A}_{i}\left(\theta_{i}\right)$; (3) Participant i can get $u_{i}=\left(a_{1}, a_{2}, \cdots a_{n} ; \theta_{i}\right)$.

2.1.2. Static Bayesian Game Equilibrium (Bayesian Nash Equilibrium ): Bayesian Nash Equilibrium: Incomplete information static game among $\mathrm{n}$ people pure strategic Bayesian Nash Equilibrium:

$G=\left\{A_{1}, A_{2}, \cdots A_{n} ; \theta_{1}, \theta_{2}, \cdots \theta_{n} ; p_{1}, p_{2}, \cdots p_{n} ; u_{1}, u_{2}, \cdots u_{n}\right\}$ is a type interdependent strategy combination $\left\{a_{i}^{*}\left(\theta_{i}\right)\right\}_{i=1}^{n}$, and every participant $i$ is in the given type utility function $v_{i}$. In other word, the strategy combination $a^{*}=\left(a_{1}^{*}\left(\theta_{1}\right), a_{2}^{*}\left(\theta_{1}\right), \cdots a_{n}^{*}\left(\theta_{1}\right)\right)$ is a kind of Bayesian Nash Equilibrium, and for all i:

$a_{i} \in \mathrm{A}_{i}\left(\theta_{i}\right),{ }_{i}^{*} \in \underset{a_{j}}{\arg \max } \sum_{\theta_{-i}} p_{i}\left(\theta_{-i} \mid \theta_{i}\right) \cdot u_{i}\left(a_{i}, a_{-i}^{*}\left(\theta_{-i}\right) ; \theta_{i}, \theta_{-i}\right)$

Bayesian Nash Equilibrium is the natural progression of Nash Equilibrium in the incomplete information game. In static incomplete information game, all participants act in the same time, so they don't have opportunities to observe other people's choice. Given others' strategic choice, every participant's optimal choice depends on their own types. Since every participant can only know about the probability distribution of other participants' types, not their real types, so they can't know exactly about what kind of strategy will others choose in fact. However, they can accurately predict how others' choices relying on their own types. In this background, his or her aim of decision is to 
maximize their own expected utility on the condition of given own type and strategies depending on others' types. And Bayesian Nash Equilibrium is such a kind of strategy combination: In the condition of given own type and strategies depending on others' types, the expected utility of every participant has been maximized, that is to say, on one would choose other strategies.

\subsection{Dynamic Bayesian Game}

2.2.1. Basic Thinking: In incomplete information dynamic game, firstly naturally choose the type of participants, which only the participant himself knows but other participants can't know. After the natural choice, participants begin to act, since the actions of participants have orders, so the later ones can observe the former ones' actions, which still can't observe the former ones' type. However, the actions of participants are typecontingent, and the actions of every participant all transit some information related to their own types. So the later actors can infer the former actors' type or correct the prior beliefs which is used to predict their types (probability distribution) by observing the actions chosen by the former actors, and then they can choose their optimal actions. Therefore, incomplete information dynamic game does not only participate the process of action choosing, but also is the process that participants continuously correct their beliefs. It requires: Firstly,in every information set, there must be a definition belonging to one of the probability distributions (beliefs) of all decision nodes in this information set; Secondly, in given information set, among every probability distribution and other participants' subsequent strategies, the actions of the participants must be optimal; Thirdly,every participant corrects posterior probability according to Bayesian law and Equilibrium strategy.

\subsubsection{The Mathematical Description of Refining Bayesian Nash Equilibrium:}

Assuming that there are n participants, and the type of participant i is $\theta_{i} \in \Theta_{i}, \theta_{i}$ being private information. $p_{i}\left(\theta_{-i} \mid \theta_{i}\right)$ is the prior probability that the participant $\mathrm{i}$ belonging to type $^{\theta_{i}}$ thinks that other n-1 participants belong to type $\theta_{-i}=\left(\theta_{1}, \cdots, \theta_{i-1}, \theta_{i+1}, \cdots, \theta_{n}\right)$. Set $S_{i}$ as the strategic space of $\mathrm{i}$ and $s_{i} \in S_{i}$ is the specific strategy (relying on type $\theta_{i}$ ). $a_{-1}^{h}=\left(a_{1}^{h}, \cdots, a_{i-1}^{h}, a_{i+1}^{h}, \cdots, a_{n}^{h}\right)$ is the action combination of another n-1 participants observed by participant $\mathrm{i}$ in No. $\mathrm{H}$ information set, which is one part of strategy combination $S_{-i}=\left(s_{1}, \cdots, s_{i-1}, s_{i+1}, \cdots, s_{n}\right)$. While $\tilde{p}\left(\theta_{-i} \mid a_{-i}^{h}\right)$ is the posterior probability that participant $\mathrm{i}$ thinks that another n-1 participants belongs to type $\theta_{-i}=\left(\theta_{1}, \cdots, \theta_{i-1}, \theta_{i+1}, \cdots, \theta_{n}\right)$ in the condition of observing $a_{-i}^{h}$, and $\tilde{p}_{i}$ is the combination of all posterior probability $\tilde{p}\left(\theta_{-i} \mid a_{-i}^{h}\right) \cdot u_{i}\left(s_{i}, s_{-i}, \theta_{i}\right)$ is the utility function of i. So the refining Bayesian Nash Equilibrium can be defined as followed:

Refining Bayesian Nash Equilibrium is the combination of a strategy combination $s_{i}^{*}=\left(s_{1}^{*}\left(\theta_{1}\right), \cdots s_{n}^{*}\left(\theta_{n}\right)\right)$ and a posterior probability combination $\tilde{p}=\left(\tilde{p}_{1}, \cdots, \tilde{p}_{n}\right)$, which can meet the conditions as followed:

For all participants i in every information set h, they meet:

$$
s_{i}^{*}\left(s_{-i}, \theta_{i}\right) \in \arg \max \sum_{\theta_{-i}} \tilde{p}_{i}\left(\theta_{-i} \mid a_{-i}^{h}\right) \cdot u_{i}\left(s_{i}, s_{-i}, \theta_{i}\right)
$$


$\tilde{p}\left(\theta_{-i} \mid a_{-i}^{h}\right)$ is obtained by using Bayesian law to observe $a_{-i}^{h}$ and optimal strategy $s_{-i}^{*}$ from prior probability $p_{i}\left(\theta_{-i} \mid \theta_{i}\right)$ (under possible condition).

\subsection{Analytical Procedure}

This article will establish two models.Model I is the basic model,analytical procedure:the first step is variable assumption and establishing model I .The second step is model analysis,that includes Proposition 1and proof. The third step is discussion,describe problems found.Model II is improved model,analytical procedure:the first step is establishing model II ,The second step is model analysis,that includes Proposition 2 and proof .The third step is discussion, about that must meet two conditions to reach the equilibrium of Proposition 2.

\section{The Analysis, Solution and Discussion of the Model}

Game theory is used to analyze the cooperation and game behavior of food enterprises and supervision administrations during product safety supervision, and also to analyze the implementation and supervision problem of safety investment. By establishing model, the factors that influence food enterprises to cheat consumers and the reasons of weak supervision in food safety are dissected. After model improving, make it clear of main supervised objects and supervision measures of government, and of the necessary conditions for government to implement effective supervision.

\subsection{Game Model I}

3.1.1. Basic Assumption: According to the present situation of our food safety supervision and related food safety supervision system, the following basic assumption is made for the game model of food safety supervision:

The combination of participants in the set is $T=\{1,2\}$, and 1 represents for food safety supervision administrations, while 2 is for food enterprises.

$\Phi=\left\{\theta_{1}, \theta_{2}\right\}$ represents for the type space of participant 1 , in which, $\theta_{1}$ stands for the supervision of food safety supervision administrations to food enterprises, while $\theta_{2}$ means that food safety supervision administrations do not supervise food enterprises.

$M=\left\{m_{1}, m_{2}\right\}$ represents for the action space of participant in the set 1 . When $m=m_{1}$, the supervision of food safety supervision administrations to food enterprises is constantly effective and succeed to find out the illegal behaviors of food enterprise, with the supervision costs of $C_{1}$. When $m=m_{2}$, food safety supervision administrations do not supervise food enterprises or the power of supervision is weak, which means failure supervision, and that they do not find out the illegal behaviors of food enterprise, with the supervision costs of $C_{2}$, and $C_{1}>C_{2}$.

The action space of participant in the set 2 is $\left\{a_{1}, a_{2}\right\}$, in which, $a_{1}$ represents for the irregularity of food enterprise, while $a_{2}$ is for regularity of food enterprise.

When $\theta=\theta_{2}$, there must be $m=m_{2}$. Because when food safety supervision administrations do not supervise food enterprises, the results are sure that the illegal food enterprises won't get punishment.

Use $U(\theta, m, a)$ to represents revenue function of the type-contingent of participant in the set $i(i=1,2)$. According to the above assumption, we can know that: 


$$
\begin{array}{ll}
U_{1}=\left(\theta_{1}, m_{1}, a_{1}\right)=F-C_{1}, & U_{2}=\left(\theta_{1}, m_{1}, a_{1}\right)=-F-Q \\
U_{1}=\left(\theta_{1}, m_{1}, a_{2}\right)=-C_{1}, & U_{2}=\left(\theta_{1}, m_{1}, a_{2}\right)=I \\
U_{1}=\left(\theta_{1}, m_{2}, a_{1}\right)=-C_{2}, & U_{2}=\left(\theta_{1}, m_{2}, a_{1}\right)=Q \\
U_{1}=\left(\theta_{1}, m_{2}, a_{2}\right)=-C_{2}, & U_{2}=\left(\theta_{1}, m_{2}, a_{2}\right)=I \\
U_{1}=\left(\theta_{2}, m_{2}, a_{1}\right)=0, & U_{2}=\left(\theta_{2}, m_{2}, a_{1}\right)=Q \\
U_{1}=\left(\theta_{2}, m_{2}, a_{2}\right)=0, & U_{2}=\left(\theta_{2}, m_{2}, a_{2}\right)=I
\end{array}
$$

In the above formula, $\mathrm{F}$ stands for the punishment of supervision administration to

\begin{tabular}{|c|c|c|c|}
\hline & \multicolumn{3}{|c|}{ Government } \\
\hline & \multicolumn{2}{|c|}{ Supervision $\theta_{1}(p)$} & No Supervision \\
\hline illegal $a_{1}(q)$ & $\begin{array}{r}\text { Supervision of } \\
\text { Strong Power } m_{1}\end{array}$ & $\begin{array}{r}\text { Supervision of } \\
\text { Weak Power } m_{2}\end{array}$ & $\theta_{2}(1-p)$ \\
\hline Enterprise & $F-C_{1},-Q-F$ & $-C_{2}, Q$ & $0, Q$ \\
\hline legal $a_{2}(1-q)$ & $-C_{1}, I$ & $-C_{2}, I$ & $0, I$ \\
\hline
\end{tabular}
illegal food enterprises, and $F<C_{1}-C_{2}$ says that the punishment power to illegal food enterprises is weak. In addition, the revenues of illegal food enterprises are higher than those of legal ones, so $I<Q$, according to the above assumption, game model I can be established, as showed in the Table 2.

Table 2. Game Model I

3.1.2. Model Analysis: Proposition 1: The sub-game refining Bayesian Nash Equilibrium of Model I is that the participant in the set 1 always takes weak supervision or no supervision, while the participant in the set 2 will be illegal or not according to the action types of supervision administrations. The sub-game refining Bayesian Nash Equilibrium of Model I is stated as $\left(m^{*}(\theta), a^{*}(\theta), p(\theta / m)\right)$ in mathematical language, during which, the participant in the set 1 takes mix-up strategy, that is $m^{*}(\theta)=\left\{\begin{array}{l}m_{1}, \theta=\theta_{1} \\ m_{2}, \theta=\theta_{2}\end{array}\right\}$, while the participant in the set 2 uses separation strategy, namely $a^{*}(m)=\left\{\begin{array}{l}a_{1}, m=m_{1} \\ a_{2}, m=m_{2}\end{array}\right\}$.

So the information is judged as:

$p\left(\theta_{1} / m_{1}\right)=p\left(\theta_{2} / m_{2}\right)=1 ; \quad p\left(\theta_{1} / m_{2}\right)=p\left(\theta_{2} / m_{1}\right)=0$.

Proof:The participant in the set 1 of Model I takes mix-up strategy: $m^{*}(\theta)=\left\{\begin{array}{l}m_{1}, \theta=\theta_{1} \\ m_{2}, \theta=\theta_{2}\end{array}\right\},\left(m_{1}, m_{2}\right)$ for short.

If the participant in the set takes mix-up strategy $\left(m_{1}, m_{2}\right)$, then the information judgment of the participant in the set 2 :

$p\left(\theta_{1} / m_{1}\right)=p\left(\theta_{2} / m_{2}\right)=1 ; \quad p\left(\theta_{1} / m_{2}\right)=p\left(\theta_{2} / m_{1}\right)=0$, so his or her choice is $\max _{a_{i}} \sum_{\theta} U_{2}\left(\theta_{j}, M_{k}, a_{i}\right)$.

When $m=m_{1}$, the choice of the participant in the set 2 is : 


$$
\begin{aligned}
& \max _{a_{i}} \sum_{\theta} U_{2}\left(\theta_{j}, M_{k}, a_{i}\right) p\left(\theta_{j} / m_{1}\right) \\
& =\max U_{2}\left(\theta_{1}, m_{1}, a_{i}\right) \times 1 \\
& =\max \left\{U_{2}\left(\theta_{1}, m_{1}, a_{1}\right), U_{2}\left(\theta_{1}, m_{1}, a_{2}\right)\right\} \\
& =I
\end{aligned}
$$

Now $a^{*}\left(m_{1}\right)=a_{2}$.

When $m=m_{2}$, the choice of the participant in the set 2 is :

$$
\begin{aligned}
& \max _{a_{i}} \sum_{\theta} U_{2}\left(\theta_{j}, M_{k}, a_{i}\right) p\left(\theta_{j} / m_{2}\right) \\
& =\max U_{2}\left(\theta_{1}, m_{2}, a_{i}\right) \times 1 \\
& =\max \left\{U_{2}\left(\theta_{1}, m_{2}, a_{1}\right), U_{2}\left(\theta_{1}, m_{2}, a_{2}\right)\right\} \\
& =Q
\end{aligned}
$$

Now $a^{*}\left(m_{1}\right)=a_{1}$.

When the participant in the set 2 takes separation strategy $a^{*}(m)=\left\{\begin{array}{l}a_{1}, m=m_{1} \\ a_{2}, m=m_{2}\end{array}\right\}$, the choice of the participant in the set 1 is : $\max _{m_{k}} U_{1}\left(\theta_{j}, m_{k}, a^{*}\left(m_{k}\right)\right)$.

When $\theta=\theta_{1}$

$$
\begin{aligned}
& \max _{m_{k}} U_{1}\left(\theta_{1}, m_{k}, a_{1}\right) \\
& =\max \left\{U_{1}\left(\theta_{1}, m_{1}, a_{1}\right), U_{1}\left(\theta_{1}, m_{2}, a_{1}\right)\right\} \\
& =\max \left(F-C_{1}, C_{2}\right) \\
& =-C_{2}
\end{aligned}
$$

Now $m^{*}\left(\theta_{1}\right)=m_{2}$.

When $\theta=\theta_{2}$

$$
\begin{aligned}
& \max _{m_{k}} U_{1}\left(\theta_{2}, m_{k}, a_{2}\right) \\
& =\max U_{1}\left(\theta_{2}, m_{2}, a_{2}\right) \\
& =0 \\
& =-C_{2}
\end{aligned}
$$

There always meets $m^{*}\left(\theta_{2}\right)=m_{2}$.

So far, the Proposition 1 has been proven. The equilibrium state of Model 1 is that during the practical operation of food safety supervision, the food enterprises will take illegal or legal strategy according to the supervision power. Because of high costs, the supervision administrations will take weak supervision or no supervision action in the drive of profit of department maximized, which in another hand, creates the condition for food enterprises' illegal production.

3.1.3. Discussion: The equilibrium state of model reflects a crucial problem which exists in present food safety. Because of high costs, the supervision administrations will take weak supervision or no supervision action in the drive of profit of department maximized, which in another hand, creates the condition for food enterprises' illegal production. It indulges the illegal production of food enterprises and results in the constant happening of food safety issues in our country. According to model conclusion to analyze the present 
food safety supervision system, we can find out the problems of our country's food safety supervision, which mainly show in the following aspects: Initially, the punishment power to illegal food enterprises is not enough and can not show its deterrent force. Secondly, the punishment power is too weak to cover the high costs of supervision implementation. The Food Safety Law issued in June,2009 has strengthened the punishment power to illegal behaviors in the field of food safety, especially the regulation that the consumers whose interests and rights are damaged can demand ten times compensation, which does not only mean the protection for consumers, but also shows the determination to severely punish the illegal enterprises

The liability system of food safety supervision implements weakly, since the administrations that take weak supervision or no supervision actions do not bear their corresponding liability. Establishing food safety supervision responsibility system and the investigating system of responsibility are proposed in The State Council Decision on Further Strengthening Food Safety, of which the principle is that one supervision link is responsible by one supervision administration, and that takes dividing management as main means assisted by variety supervision. In this way, we can further definite the food safety work and responsibilities of ministries like Agriculture, Sanitation, Quality Inspection and Industry and Commerce. In the meantime, the Decision also proposed to strengthen the responsibility of local governments to food safety supervision, and demanded that the local governments should take general responsibility to local food safety, what's more, they also should establish and perfect the coordination system for food safety organizations, for the purpose of solving the food safety problem timely. However, seen from the food safety incidents in our country recently, the establishing of responsibility system in our food safety supervision did not reach the purpose of both curing symptoms and diseases while stressing on diseases curing. The main reason relies on weak implementation of responsibility system which don't play its role entirely.

During supervision, the governments do not have corresponding system of rewards and penalties to food supervision administrations, namely incentive and constraint mechanism, which causes that the supervision administrations do not have enough motivation to do supervision, and then influences the supervision effect. All these lead to failure establishment of the long-term mechanism of food safety supervision.

\subsection{Improved Model II}

In the analysis of Model I, we can conclude that the main reasons leading to food safety supervision administrations' weak supervision or no supervision action are high supervision costs and the lack of incentive mechanism. So in the Model II, it will stress on these two aspects to further improve and perfect. Assuming that there are measures of rewards and penalties for national supervision administrations to local ones, namely matched incentive and constraint mechanism, and in the same time, the responsibility system of administrations has been implemented, then when supervision succeeds, reward the supervision administrations. Conversely, if fails, they should bear corresponding responsibilities and receive corresponding penalties. In addition, the punishment power to illegal food enterprises should be stronger.

3.2.1. Model Establishment: On the basis of Model I, introduce related new variable. Set $F^{\prime}$ as new punishment power of administrations to illegal enterprises, $F^{\prime}>C_{1}-C_{2}$ and $F^{\prime}>F . f$ represents the punishment to the failure supervision of supervision administrations, while $b$ is the reward for its successful punishment. After making proper adjustment to Model I, establish Model II, and its game matrix is showed in Table 3. 
Table 3. Game Model II

\begin{tabular}{cccc}
\hline & \multicolumn{3}{c}{ Government } \\
\cline { 2 - 4 } Supervision $\theta_{1}(p)$ & No Supervision \\
\hline \multirow{2}{*}{ illegal $a_{1}(q)$} & Supervision of & Supervision of & $\theta_{2}(1-p)$ \\
& Strong Power $m_{1}$ & Weak Power $m_{2}$ & \\
Enterprise & $F^{\prime}-C_{1}+b$, & $-C_{2}-f, Q$ & $-f, Q$ \\
legal $a_{2}(1-q)$ & $-Q-F^{\prime}$ & $-C_{2}, I$ & $-f, I$ \\
\hline
\end{tabular}

3.2.2. Model Analysis: Proposition 2: When the punishment power to illegal enterprises is strong enough and $f>C_{1}-C_{2}$, then the separation strategy $\left[\left(m_{1}, m_{2}\right),\left(a_{2}, a_{1}\right), p \in(0,1)\right]$ is the sub-game refining Nash Equilibrium.

Proof:If the participant in the set 1 takes separation strategy $\left(m_{1}, m_{2}\right)$, then the information judgment of the participant in the set 2 :

$p\left(\theta_{1} / m_{1}\right)=p\left(\theta_{2} / m_{2}\right)=1 ; \quad p\left(\theta_{1} / m_{2}\right)=p\left(\theta_{2} / m_{1}\right)=0$, so his or her choice is $\max _{a_{i}} \sum_{\theta} U_{2}\left(\theta_{j}, M_{k}, a_{i}\right)$

When $m=m_{1}$, the choice of the participant in the set 2 is :

$$
\begin{aligned}
& \max _{a_{i}} \sum_{\theta} U_{2}\left(\theta_{j}, M_{k}, a_{i}\right) p\left(\theta_{j} / m_{1}\right) \\
& =\max U_{2}\left(\theta_{1}, m_{1}, a_{i}\right) \times 1 \\
& =\max \left\{U_{2}\left(\theta_{1}, m_{1}, a_{1}\right), U_{2}\left(\theta_{1}, m_{1}, a_{2}\right)\right\} \\
& =I
\end{aligned}
$$

Now $a^{*}\left(m_{1}\right)=a_{2}$.

When $m=m_{2}$, the choice of the participant in the set 2 is :

$$
\begin{aligned}
& \max _{a_{i}} \sum_{\theta} U_{2}\left(\theta_{j}, M_{k}, a_{i}\right) p\left(\theta_{j} / m_{2}\right) \\
& =\max U_{2}\left(\theta_{1}, m_{2}, a_{i}\right) \times 1 \\
& =\max \left\{U_{2}\left(\theta_{1}, m_{2}, a_{1}\right), U_{2}\left(\theta_{1}, m_{2}, a_{2}\right)\right\} \\
& =Q
\end{aligned}
$$

Now $a^{*}\left(m_{1}\right)=a_{1}$.

When the participant in the set 2 takes separation strategy $a^{*}(m)=\left\{\begin{array}{l}a_{1}, m=m_{2} \\ a_{2}, m=m_{1}\end{array}\right\}$, the choice of the participant in the set 1 is : $\max _{m_{k}} U_{1}\left(\theta_{j}, m_{k}, a^{*}\left(m_{k}\right)\right)$.

When $\theta=\theta_{1}$,

$$
\begin{aligned}
& \max _{m_{k}} U_{1}\left(\theta_{1}, m_{k}, a_{i}\right) \\
& =\max \left\{U_{1}\left(\theta_{1}, m_{1}, a_{2}\right), U_{1}\left(\theta_{1}, m_{2}, a_{1}\right)\right\} \\
& =\max \left(-C_{1},-C_{2}-f\right)
\end{aligned}
$$




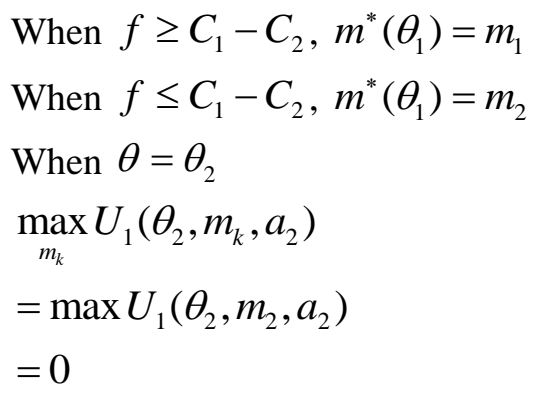

There always meets $m^{*}\left(\theta_{2}\right)=m_{2}$.

Through the deduction above, Proposition 2 has been proven. We can conclude that when the punishment power is strong enough and $f \geq C_{1}-C_{2}$, supervision administrations and food enterprises all take separation strategy. So the separation strategy is the sub-game Bayesian Nash Equilibrium.

3.2.3. Discussion: It must meet two conditions to reach the equilibrium of Proposition 2 . They are: first, Strengthen the punishment power to illegal enterprises and play its deterrent function. Improve the level of optimal safe payment of food enterprises to decrease theirs probability to be illegal. Second,Implement the responsibility system of supervision administrations and establish corresponding incentive and constraint mechanism. What's more, increase the optimal supervision power of relative administrations and their enthusiasm in supervision to ensure that the governments can supervise the food enterprises under the condition of smaller probability to be illegal. Initially, the punishment power to illegal enterprises should be strong enough. That is to say, the compensation of illegal behaviors shall be higher than their profits obtained during their irregularities, and in this way, the probability for enterprises to be illegal can be decreased. For supervision administrations, if they want to reach effectiveness of food safety supervision, they must implement responsibility system and reward or punish the corresponding administrations severely. Otherwise, the illegal production of food enterprises can not be restrained effectively, let alone the effective solution to food safety issue. In a word, the two conditions can not be lacking of anyone. When the two conditions meet in the same time, then it reaches the equilibrium in the Proposition 2. Otherwise, it will fall into the range equilibrium in the Proposition 1.

\section{Conclusion}

It can be seen from the above analysis that the changes in the food safety supervision policies have influence on the food enterprises. Seen from the equilibrium of Proposition 1 , because of government's high costs of supervision, in the drive of profits of department maximized, supervision administrations usually take weak supervision or no supervision action, which creates environment for food enterprises to product illegally. By changing supervision policies, we can not only strengthen the punishment power to illegal enterprises and implement the responsibility system of supervision administration, but also can improve the level of supervision power and enthusiasm to reach the equilibrium of Proposition 2. Therefore, under the condition of establishing correct supervision regulations and providing perfect supervision system, food safety issue can be solved effectively. We ought to take measures from the following aspects:

Establish a more perfect food safety law system to make the rights and liabilities allocation among every supervision administration more explicit, and perfect the system of rewards and penalties of food safety supervision. In addition, though there are many constraint factors in the establishment of food safety national standard, seen from strategic level and in the long run, we should be more innovative in establishing food safety standard and participate more or lead in establishing food safety national standard. 
Build a more strong coordination institute among every administration, even setting a special food safety supervision council in the State Council. Our country should found food safety supervision council constituted by related functional departments of government as early as possible, which is special in charge of organizing and coordinating each department of the government in the supervision to our country's food safety and providing suggestions for government when it establishes food safety policies. Besides, it still can study and propose food safety security system, or investigate and estimate the state of food safety to put forward some improving measures.

Rationally divide the labor of every food safety institute in the government, matching theirs functions of each department. Concentrate the supervision right properly and cut down the quantities of supervision administrations, which can reduce the difficulties of coordinating, avoid opportunism behaviors and decrease the risk of excessive division of authorities. The feasible idea is that according to the principle of unifying administrative power and function and the characteristics of food safety overflow effect, reduce the supervision among multi-level regulatory agencies and incentive costs and the food safety regulatory power should be rationally allocated among central government, provincial governments and the local governments interior to provincial ones, which gives priority to the local governments interior to provincial ones. The detailed allocation of regulatory power is as followed: Since the overflow effect of the input and output of food involves the home and abroad, so the regulatory power of the safety of input and output food belongs to central government; While the overflow effect of food consumption link is main in local areas, so its regulatory power main belongs to the local governments interior to provincial ones; And the overflow effect of the production of agriculture product, food processing and circulation link is between local areas and provinces, so it is responsible by provincial governments.

At last, consistent with the trend of international administrative reform, the food safety supervision will be introduced the power out of the governments, such as guilds, groups for protecting rights and interests of consumers or other civil groups, who have established a so-called "Fire Alarm" mechanism, and complement the food safety supervision system led by the government.

\section{References}

[1] S. Henson and J. Caswell. "Food Safety Regulation : an Overview of Contemporary Issues", Food Policy, vol. 24, (1999), pp. 589-603.

[2] K. J. Arrow, M . L. Cropper and G. C. Eads, "Benefit-cost analysis in environmental, health, and safety regulation", The AEI Press, Washington D C, (1996).

[3] J. M. Antle, "Choice and Efficiency in Food Safety Policy", The AEI Press, Washington D C, (1995).

[4] S. J. Grossman, "The Information Role of Warranties and Private Disclosure about Product Quality ", Journal of Law and Economics, vol. 24, no. 1, (1981), pp. 201-211.

[5] L. Jing, "Effectiveness Analysis of China's Food Safety Regulatory System-on Study of China's Milk Industry Supervision ”, WuHan University Journal, vol. 64, no. 2, (2011), pp. 88-91.

[6] W. Keshan and L. Binglong, "Zhao Jianfeng. Analysis on Food Quality Safety Based on the Morality Risk Model ”, Guizhou Agricultural Science, vol. 4, (2007), pp.153-155.

[7] L. Renzhong, "Analysis on Food Safety Regulation Based on Repeated Game", China Soft Science Magazine, vol. 9, (2011), pp. 167-172.

[8] Freeman, "R.E. Strategic Management: A Stakeholder Approach", Pitman, Boston, (1984)

[9] Z. Lv, T. Yin and Y. Han, "WebVR-web virtual reality engine based on P2P network[J]. Journal of Networks,vol. 6, no. 7, (2011), pp. 990-998.

[10] J. Yang, J. Zhou and Z. Lv, "A Real-Time Monitoring System of Industry Carbon Monoxide Based on Wireless Sensor Networks", Sensors, vol. 15, no. 11, (2015), pp. 29535-29546.

[11] D. Jiang, X. Ying and Y. Han, "Collaborative multi-hop routing in cognitive wireless networks", Wireless Personal Communications, vol. 86, no. 2, (2016), pp. 901-923.

[12] Z. Lv, A. Halawani and S. Feng, "Multimodal hand and foot gesture interaction for handheld devices", ACM Transactions on Multimedia Computing, Communications, and Applications (TOMM), (2014), vol. 1 , no. 1.

[13] J. Hu and Z. Gao, "Distinction immune genes of hepatitis-induced heptatocellular carcinoma", Bioinformatics, vol. 28, no. 24, (2012), pp. 3191-3194. 
[14] J. Hu, Z. Gao and W. Pan, "Multiangle Social Network Recommendation Algorithms and Similarity Network Evaluation", Journal of Applied Mathematics, vol. 2013, (2013).

\section{Authors}

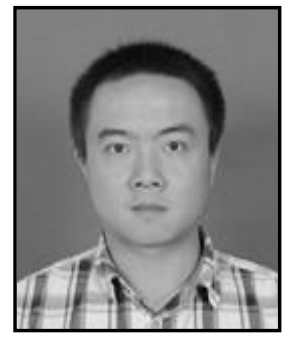

Wang Mingzhe, he was born in 1988, native of Xinxiang City, Henan Province Hohai University Ph.D., principal research areas of urban and rural sociology, Sociology of Immigration and Game Theory. 